Dicle University Journal of Engineering (DUJE)

\title{
Trend Tespiti Yapılmış Akım Gözlem İstasyonlarında Güncel Durumun Belirlenmesi
}

\section{Determination of Current Situation at Trend Observed Flow Observation Stations}

\author{
Nadire Üçler \\ Van Yüzüncü Yıl Üniversitesi, İnşaat Bölümü, Van, nadireucler@yyu.edu.tr
}

\begin{tabular}{|c|c|}
\hline GÍLERİ & ÖZET \\
\hline Makale geçmişi: & \multirow{6}{*}{ 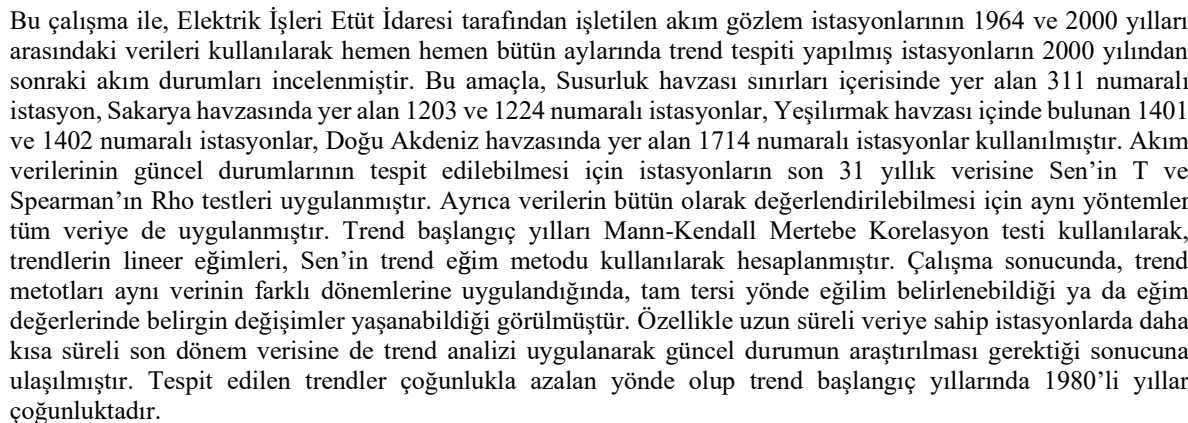 } \\
\hline Geliș: 12 Kasım 2019 & \\
\hline & \\
\hline Kabul: 27 Ocak 2020 & \\
\hline Anahtar kelimeler: & \\
\hline $\begin{array}{l}\text { Trend analizi, Sen'in T testi, } \\
\text { Spearman'ın Rho testi, Mann- } \\
\text { Kendall mertebe korelasyon testi }\end{array}$ & \\
\hline
\end{tabular}

Doi: $10.24012 /$ dumf. 645717

\begin{tabular}{l} 
ARTICLE INFO \\
\hline Article history: \\
Received: 12 December 2019 \\
Revised: 5 January 2020 \\
Accepted: 27 January 2020 \\
\hline Keywords: \\
Trend analysis, Sen's T test, \\
Spearman's Rho test, Mann \\
Kendall rank correlation test
\end{tabular}

Kendall rank correlation test

\begin{abstract}
In this study, the current situations of the stations in which trend detected in almost all months in the study conducted using flow data between 1964 and 2000 is examined. For this purpose, station 311 within the boundaries of Susurluk basin, stations 1203 and 1224 in Sakarya basin, stations 1401 and 1402 in Yeşilirmak basin and stations 1714 in East Mediterranean basin were used. Sen's T and Spearman's Rho tests were applied to the the last 31 years data of the stations in order to determine the current status of the flow data. Also to evaluate the data as a whole same methods were applied to all data too. Trend start years were calculated using Mann-Kendall Rank Correlation test and linear slope of trends were calculated using Sen's trend slope method. As a result of the study, when trend methods are applied to different periods of the same data, it is seen that trend can be determined in opposite direction or significant changes in slope values can be observed. It is concluded that the current situation should be investigated by applying trend analysis to shorter last term data especially in the stations with long term data. The trends are mostly declining and 1980s are the majority in the beginning of the trend.
\end{abstract}

\footnotetext{
* Sorumlu yazar / Correspondence

Nadire ÜÇLER

$\triangle$ nadireucler@yyu.edu.tr

Tel:+904322251414
} 


\section{Giriș}

Trend analiz metotları, zaman serilerindeki bir değişkenin eğilimini inceleyen yöntemlerdir. Bir zaman serisinde, ilgili değişkeninin yıllar içinde artan ya da azalan eğilim gösterip göstermediği veya sabit kalıp kalmadığını incelerler. Eğilim belirleme ve tespit edilen bir eğilimin istatistiksel önemini analiz etmek amaciyla kullanılan parametrik ve parametrik olmayan yöntemlerin her ikisinin de artıları ve eksileri vardır. Bu sebeple çalışma için hangi yöntemin seçileceği veri kümesinin özelliklerine ve koşullara bağlıdır [1].

Parametrik yöntemlerin aksine eksik, kısıtlı veya bağımlı verilere de uygulanabilen non-parametrik metotlar eksik verisi olabilen ve genellikle normal dağılmayan hidro-meteorolojik verilere uygulanabilmektedir [2-4].

Küresel iklim değișikliği ve bunun etkilerine olan ilginin artması sonucu sıcaklık [5-8], yağgş [916], nem [17,18], kar [19, 20], buharlaşma [21], güneşlenme süresi [22, 23], akış [24-27] gibi parametrelere trend analiz metotları sıklıkla uygulanmaktadır.

Bu çalışmanın amacı, daha önce Özel tarafından [28], istasyonların açıldığı tarihten çalışmanın yapıldığı tarihe kadar olan (1964 ve 2000 yılları arası) ortalama aylık akım verileri kullanılarak hazırlanmıș tez çalıșmasında hemen hemen bütün aylarda azalan ya da artan trend tespit edilen istasyonların 2000 yılından sonraki akım verilerinin daha önce belirlenen trende uygun gerçekleşip gerçekleşmediğini araştırmaktır. Trend metotlarının uygulanabilmesi için en az 30 y1llık veriye ihtiyaç olduğundan istasyonların son durumlarının belirlenebilmesi için istasyona ait 1981-2011 yılları arasındaki son 31 yıllık veriye seçilen yöntemler uygulanmıştır. Ayrıca veriyi bir bütün olarak değerlendirebilmek için istasyonların açıldığ1 ve kapandığı tarihler arasındaki tüm veriye (1964-2011) trend belirleme metotları uygulanmıştır. Trend belirlenen aylar için trend eğimleri ve trend başlangıç yılları hesaplanmıştır.

\section{Materyal ve Metot}

Çalışma kapsamında, Elektrik İşleri Etüt İdaresi (EİEI) tarafından işletilmiş olan istasyonlara ait veriler Devlet $\mathrm{Su}$ İşleri Akım Gözlem Y1llıklarından temin edilerek kullanılmıștır [29]. Trend metotları Susurluk havzası sinırları içerisinde yer alan ve daha önce yapılan çalışmada 9 ayda azalan trend tespit edilen 311 numaralı istasyon, bütün aylarda azalan trend tespit edilen ve Sakarya havzasında yer alan 1203 ve 1224 numaralı istasyonlar, 7 ayda artan 3 ayda azalan trend tespit edilen, Yeşilırmak havzası içinde bulunan 1401 numaralı istasyon ve aynı havzada 6 ayda artan trend tespit edilen 1402 numaralı istasyon ve 8 ayda azalan trend tespit edilen, Doğu Akdeniz havzasında yer alan 1714 numaralı istasyona uygulanmıştır. İstasyonların Türkiye haritası üzerindeki yerleri Şekil 1'de gösterilmiştir.

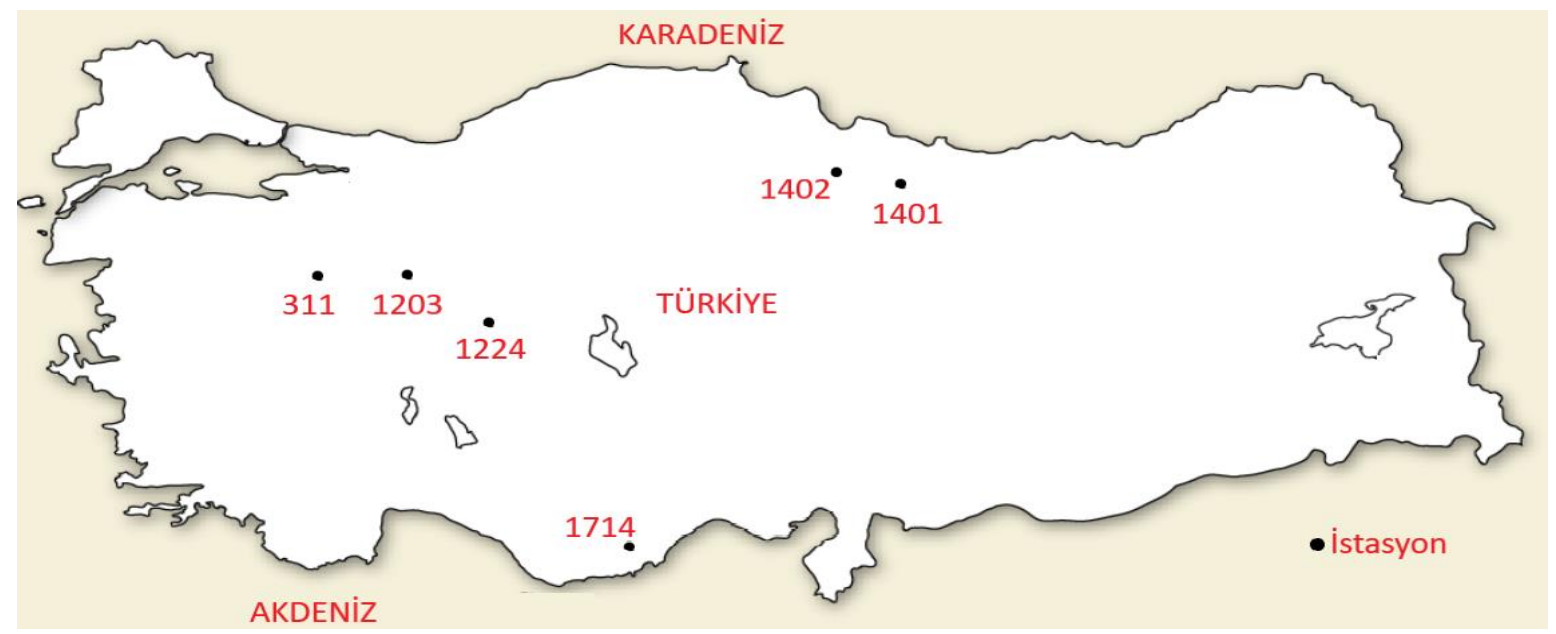

Şekil 1. Çalışmada kullanılan istasyonlar

Figure 1. Stations used in the study 
$\mathrm{Bu}$ araştırmada, nehir akımları aylık verilerinin trend analizini yapmak için Sen'in $T$, Spearman'1n Rho testleri, trendlerin eğimlerini belirlemek için Sen'in Trend Eğim metodu ve trend başlangıç yıllarının belirlenmesi amacıyla da Mann-Kendall Mertebe Korelasyon testi kullanılmıştır.

\section{Sen'in T Testi}

1968 yılında Sen [30] tarafından önerilmiş ve 1980 yılında Farrell tarafından geliştirilmiş olan Sen'in T testi siralı bir rank testidir [3]. Test istatistiği, dağılımdan bağımsızdır ve mevsimsel olaylardan etkilenmez, aşağıda verilen işlem sirasiyla hesaplanabilir:

Burada; i: yıllar $(i=1,2, \ldots \ldots, n)$ ve $j: \operatorname{aylar}(j=1$, $2, \ldots, 12)$ olmak üzere; $X_{\mathrm{ij}}$, akım gözlem istasyonunda ölçülen debi değeridir.

$\mathrm{j}$ ayın ortalaması denklem 1 ile ifade edilir.

$$
X_{. j}=\frac{\sum_{i} X_{i j}}{n}
$$

Mevsimsellik etkisini yok etmek için $\mathrm{n}$ yıllık dataların her bir ayından o ayın ortalaması çıkarılarak $X_{\mathrm{ij}}-X_{. j}$ hesaplanır. 1'den başlayıp 12× n'e kadar olan tüm farkların sırası (2) denklemi kullanılarak belirlenir.

$$
R_{i j}=\operatorname{Rank}\left(X_{i j}-X_{. j}\right)
$$

Her bir ayın ranklarının ortalaması (3) denklemi, her bir yılın ranklarının ortalaması ise (4) denklemi kullanılarak hesaplanır.

$$
\begin{aligned}
& R_{. j}=\frac{\sum_{i} R_{i j}}{n} \\
& R_{i .}=\frac{\sum_{j} R_{i j}}{n}
\end{aligned}
$$

Sonuç olarak Sen'in T test istatistiği denklem 5 kullanılarak hesaplanır. (Burada $\mathrm{m}=1$ 'dir.)

$$
\begin{gathered}
T=\left[\frac{12 m^{2}}{n(n+1) \sum_{i, j}\left(R_{i j}-R_{. j}\right)^{2}}\right]^{1 / 2}\left[\sum_{i=1}^{n}(i-\right. \\
\left.\left.\frac{n+1}{2}\right)\left(R_{i .}-\frac{n m+1}{2}\right)\right]
\end{gathered}
$$

Mutlak T değerinin, belirlenen $\alpha$ önem seviyesine karşılık gelen normal dağılım değeri z'den büyük olması halinde, trendin olmadığı varsayımının yapıldı $\breve{g}_{1} \mathrm{H}_{\mathrm{o}}$ hipotezi reddedilerek belirgin bir trendin olduğu tespit edilmiş olur.

\section{Spearman'ın Rho Testi}

$\mathrm{Bu}$ test sıra istatistiğine dayanır. Veri serisinde lineer trend varlığını belirlemek amaçlı kullanılan basit bir yöntemdir. $\mathrm{R}_{(\mathrm{xi})}$ sira istatistiğini ifade eder. Veriler küçükten büyüğe ya da tam tersi şekilde sıralanarak belirlenir. Gözlem serisi $\mathrm{X}=$ $\left(\mathrm{X}_{1}, \mathrm{X}_{2}, \ldots \ldots, \mathrm{X}_{\mathrm{n}}\right)$ vektörü şeklindedir. $\mathrm{H}_{0}$ (sıfır) ve $\mathrm{H}_{1}$ (alternatif) olmak üzere iki hipotez tanımlanır. $\mathrm{H}_{0}$ hipotezine göre $\mathrm{x}_{\mathrm{i}}(\mathrm{i}=1,2,3, \ldots \ldots ., \mathrm{n})$ eş olasılıklı dağılımlardır. $H_{1}$ hipotezine göre ise $X_{i}$ $(\mathrm{i}=1,2,3, \ldots \ldots ., \mathrm{n})$ zaman içinde artar ya da azalır. Testi istatistiği $r_{s}$, aşağıdaki denklemle hesaplanır.

$$
r_{s}=1-6 \frac{\left[\sum_{i=1}^{n}\left(R\left(x_{i}-i\right)^{2}\right]\right.}{\left(n^{3}-n\right)}
$$

$\left(\mathrm{X}_{\mathrm{i}}\right)$, i. verinin sıra numarasını; i, verilerin ölçüm sırasını; n, toplam gözlem adedini ifade etmektedir [31]. Spearman, belirli bir önem seviyesinde sira sayıları arasında korelasyon olmadığını gösteren maksimum $r_{s}$ değerlerini bir tablo ile vermiştir. $n>30$ için $r_{s}$ dağılımının normale yaklaşacağı kabulü ile sonuçlar için normal dağılım tabloları kullanılabilmektedir [32]. Böylelikle, $r_{s}^{\prime}$ nin test istatistiği $z$, (7) numaralı denklemle bulunur.

$$
\mathrm{z}=\mathrm{r}_{\mathrm{s}} \sqrt{1 /(\mathrm{n}-1)}
$$

Mutlak $\mathrm{z}$ değerinin belirlenen $\alpha$ önem seviyesindeki $\mathrm{Z}_{\alpha}$ değerinden büyük olması durumunda $X_{i}{ }^{\prime}$ lerin eş dağ 1 lımlı olduğu hipotezi reddedilir böylece bir trend olduğu tespit edilmiş olur.

\section{Sen'in Trend Eğim Metodu}

$\mathrm{Bu}$ metot trendlerin birim zamandaki değişimini belirlemek için kullanılan parametrik olmayan bir testtir (Sen 1968). Bu yöntem, verilerin hatalı ya da eksik olabileceği veri setlerine de uygulanabilmektedir. $x_{j}$ ve $x_{k}, j$ ve $k$ zamanlarındaki verileri ifade etmektedir. $\mathrm{j}>\mathrm{k}$ olmak üzere; $\mathrm{N}=\mathrm{n}(\mathrm{n}-1) / 2$ adet $\mathrm{Q}_{\mathrm{i}}(\mathrm{i}=1,2$,

N) değeri, (8)'deki denklem kullanılarak hesaplanmaktadır. $Q_{i}$ değerleri küçükten büyüğe $\operatorname{doğru}\left(Q_{1} \leq Q_{2} \leq Q_{3} \leq \ldots \ldots . . \leq Q_{N-1} \leq Q_{N}\right)$ şeklinde siralanmaktadır.

$$
Q_{i}=\frac{x_{j}-x_{k}}{j-k}
$$


$\mathrm{Q}_{\mathrm{i}}{ }^{\prime}$ lerin belirlenmesi ve sıralanmasının ardından, $\mathrm{N}$ tek ise (9), çift ise (10) denklemi kullanılarak, $\mathrm{N}$ adet $\mathrm{Q}_{\mathrm{i}}$ değerinin medyanı alınır. Böylece söz konusu gözlemin lineer eğimleri belirlenmiş olur.

$$
\begin{aligned}
& Q=\left\{Q_{(N+1) / 2}\right\} \\
& Q=\left\{\frac{1}{2}\left[Q_{(N) / 2}+Q_{(N+2) / 2}\right]\right\}
\end{aligned}
$$

\section{Mann-Kendall Mertebe Korelasyon İstatistiği}

Parametrik olmayan bu test, söz konusu seride zaman içinde artma ya da azalma eğilimi olup olmadığını tespit etmek amaciyla kullanılır. Testin sonucu ve varsa trendin başlangıç noktası grafik üzerinden belirlenir. Testte reel veri kullanmak yerine, verinin serideki mertebesi $\left(\mathrm{y}_{\mathrm{i}}\right)$ ile işlem yapılır. Her bir yi önceki mertebelerden büyükler sayılarak $n_{i}$ gibi bir sayı ile ifade edilir. Test istatistiği olan t'yi hesaplamak için $\mathrm{n}_{\mathrm{i}}$ 'ler toplanır.

$$
t=\sum_{i=1}^{n} n_{i}
$$

Bunun ortalama ve varyans1, Mann-Kendall test istatistiği u(t) sirasıyla,

$$
\begin{aligned}
& E(t)=\frac{n(n-1)}{4} \\
& \text { var } t=\frac{n(n-1)(2 n+5)}{72} \\
& u(t)=[t-E(t)] / \sqrt{\text { var } t}
\end{aligned}
$$

şeklinde hesaplanır [33].

Verilerde zaman içinde değişim olmadığ varsayımını, u(t)'nin sıfira yakın olduğu değerler gösterirken $u(t)$ 'nin büyük değerleri değişim olduğunu belirtir. \pm 1.96 değerine ulaşan $\mathrm{u}(\mathrm{t})$ değeri trendin \%95 önemlilik seviyesine ulaştığına işaret eder. $u^{\prime}(t)$ veri serisi içinde ters istikamette $u(t)$ ile aynı yöntemle hesaplanır. $u(t)$ ve $\mathrm{u}^{\prime}(\mathrm{t})$ grafiğinde, önce birbirlerine yaklaştıkları sonra ise uzaklaştıkları nokta değişimin başlangıcına işaret eder trend başlangıç noktasını ve trendin kuvvetini gösterir. Ancak belirgin bir trend olmadığında $\mathrm{u}(\mathrm{t})$ ve $\mathrm{u}^{\prime}(\mathrm{t})$ grafikleri birbirlerine birçok defa yakın salınımlar gösterirler.

\section{Bulgular}

Şekil 2'de yer alan grafikte, Özel [28] tarafından yapılan çalışmada bütün aylarda azalan trend tespit edilen 1203 numaralı istasyonun mart ayına ait 2000 yılı öncesi ve sonrası akım değerleri ve eğilim çizgileri görülmektedir. 2000 yılına kadar olan verilerde azalma eğilimi görülürken 2000 yılından sonraki değerlerde artan bir eğilim görülmesi akla akım verilerinin belirlenen trend sonucuna aykırı olarak gerçekleşmiş olabileceği durumunu getirmiştir.

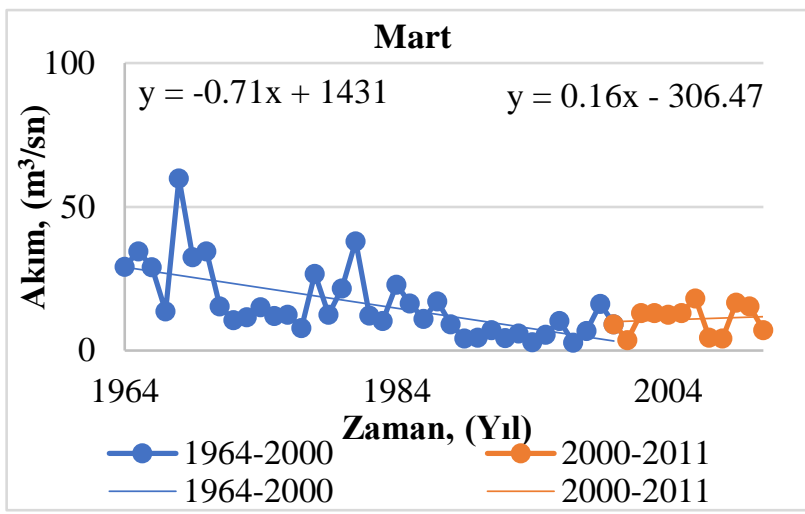

Şekil 2. 1203 no.lu istasyon, mart ayl, 2000 yıl öncesi ve sonrast akım değerleri ve ĕgilim çizgileri

Figure 2. Station 1203, March, pre-2000 and post-2000 flow values and inclination lines

Benzer şekilde daha önceki çalışmada artan trend tespit edilen Yeşilırmak havzası 1401 numaralı istasyona ait grafik (Şekil 3) incelendiğinde 2000 yılına kadar artan eğilim gösteren akım değerlerinin 2000 yılından sonra azalan yönde eğilim göstermesi daha önce trend belirlenmiş istasyonlarda son yıllarda istatistiki olarak anlamlı trend olup olmadığının araştırılması gerekliliğini doğurmuştur.

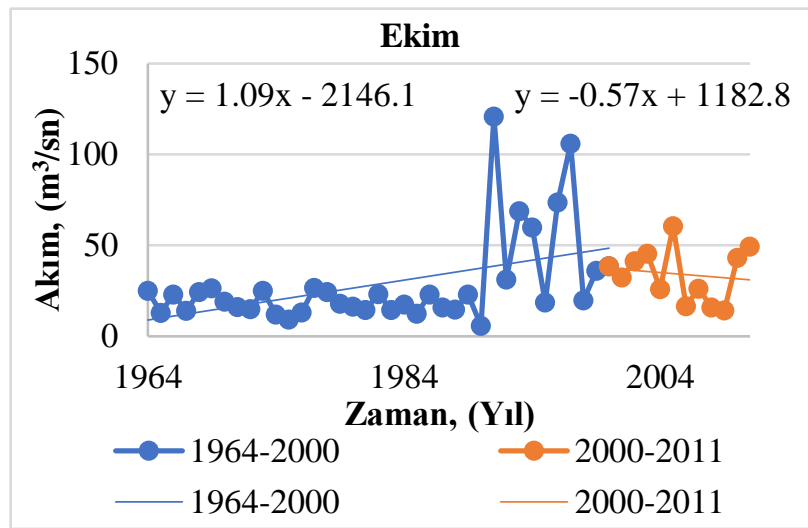

Şekil 3. 1401 no.lu istasyon, ekim ayl, 2000 yılı öncesi ve sonrasi akım değerleri ve eğilim çizgileri

Figure 3. Station 1401, October, pre-2000 and post-2000 flow values and inclination lines 
Söz konusu istasyonlara ait 1964 ve 2000 yılları arasını kapsayan 37 yıllık ilk çalışma sonuçları (ilk dönem), istasyonların son veri aldığ 2011 yılına kadar olan son durumu belirtmesi açısından 1981-2011 arasına ait 31 yıllık verilerin sonuçları (son dönem) ve mevcut bütün veriyi değerlendirmek amaçlı 1964 ve 2011 yılları arasına ait 48 yıllık veri sonuçları (uzun dönem) karşılaştırmalı olarak grafik ve tablolar yardımıyla havza bazında açıklanmıştır. Tablolarda karmaşıklığa sebep olmamak için sadece Spearman'in Rho test istatistiği sonuçlarına, trend başlangıç yıllarına ve eğim değerlerine yer verilmiştir. Artan trendler $(\uparrow)$, azalan trendler $(\downarrow)$ ve trend belirlenemeyen aylar ise $(\leftrightarrow)$ simgesiyle ifade edilmiştir.

\section{Yeşilırmak Havzası Trend Sonuçları}

Bu çalışmada, ilk dönemdeki verilerde çok sayıda ayda trend tespit edilen ve 2011 y1lına kadar düzenli ölçüm yapılan 1401 ve 1402 numaralı istasyonlar incelenmiştir. Şekil 4'te 1402 numaralı istasyon, kasım ayı, ilk ve son dönem akım değerleri ve eğilim çizgileri gösterilmektedir. 2000 yılına kadar olan kısımda belirgin şekilde artan eğilim gösteren verilerin son döneme bakıldığında azalan eğilim gösterdiği görülmektedir.

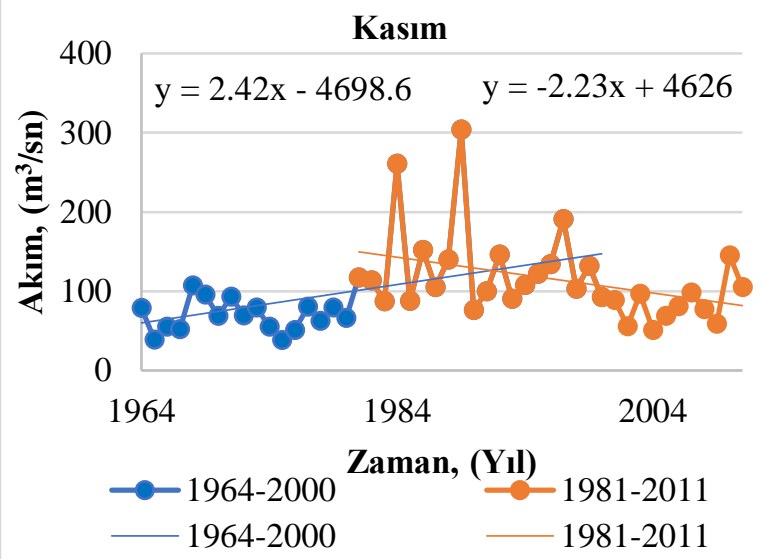

Şekil 4. 1402 numarall istasyon, kasim ayl, ilk ve son dönem akım değerleri ve eğilim çizgileri.

Figure 4. Station 1402, November, first and last period flow values and inclination lines

Şekil 5'te 1402 numaralı istasyon, son dönem, ağustos ayı, mertebe korelasyon testi $u(t)$ ve $u^{\prime}(t)$ grafiği gösterilmektedir. İki grafiğin kesim noktası trend başlangıç yılını belirtmektedir. Son dönem için yapılan trend testinde trend başlangıç yılı 1988 olarak tespit edilmiştir.

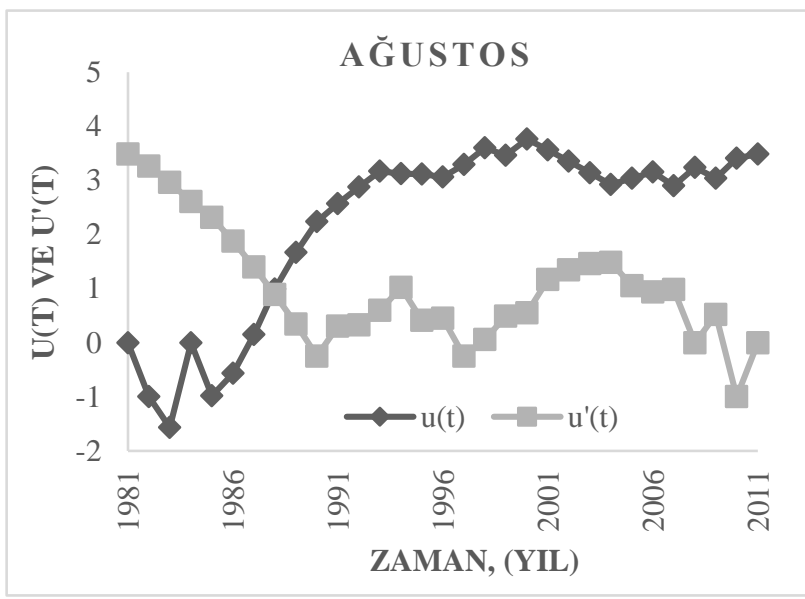

Şekil 5. 1402 no.lu istasyon, son dönem, ağustos ayl, mertebe korelasyon testi $u(t)$ ve u'(t) grafiği

Figure 5. Station 1402, final period, August, rank correlation test $u(t)$ and $u$ '( $(t)$ graphs

Tablo 1 incelendiğinde, 1401 numaralı istasyonda her üç dönemde de mart ve nisan aylarında azalan temmuz, ağustos ve eylül aylarında artan trend tespit edilmiştir. Ekim, kasım, ocak ve mayıs aylarında 1964-2000 ve 1964-2011 arasında trend belirlenirken son dönemde trend tespit edilememiştir. Son dönem mayıs ayı $\mathrm{r}_{\mathrm{s}}$ değeri (1.97) 1.96 değerinden az farkla büyük olduğundan ve Sen'in T testinde elde edilen test istatistiği değeri (1.00), 1.96 değerinden küçük olduğundan dolayı trend olmadığı sonucuna varılmıştır. Bu istasyonda en yüksek eğim 1964-2000 döneminde nisan ayında -4.79 olarak tespit edilmiştir. $\mathrm{Bu}$ istasyonda genellikle trend başlangıç y1lı olarak 1990'lı yıllar tespit edilmiştir.

1402 numaralı istasyonda kasım ayında ilk dönem için 2.01 eğim değeriyle artan, son dönemde -1.64 değeriyle azalan trend, uzun dönemde ise 0.75 değeriyle artan trend belirlenmiştir. 1402 numaralı istasyonda kasım ve ağustos aylarında her üç dönem için de trend tespit edilmiştir. İlk dönemde trend tespit edilemeyen nisan ayında 1981-2011 yılları aras1 için yapılan hesapta 1993 yılından itibaren başlayan azalan eğim tespit edilmiştir. Aynı zamanda bu eğim -5.01 değeriyle bu istasyonun en yüksek eğim değeridir. 
Tablo 1. Yeşilırmak havzası trend analiz sonuçları

Table 1. Trend analysis results of Yeşilırmak basin

\begin{tabular}{|c|c|c|c|c|c|c|c|c|c|c|}
\hline & \multirow[b]{2}{*}{ Aylar } & \multicolumn{3}{|c|}{ Trend Tespiti } & \multicolumn{3}{|c|}{ Trend Başlangiç YYll } & \multicolumn{3}{|c|}{ Trend Eğimi } \\
\hline & & $\begin{array}{l}1964- \\
2000 \\
\end{array}$ & $\begin{array}{l}1981- \\
2011\end{array}$ & $\begin{array}{l}1964- \\
2011 \\
\end{array}$ & $\begin{array}{l}1964- \\
2000\end{array}$ & 2011 & $\begin{array}{l}1964- \\
2011 \\
\end{array}$ & $\begin{array}{l}1964- \\
2000 \\
\end{array}$ & $\begin{array}{l}1981- \\
2011\end{array}$ & $\begin{array}{l}1964- \\
2011\end{array}$ \\
\hline \multirow{12}{*}{ 守 } & Ekim & $-2.31 \uparrow$ & $-1.89 \leftrightarrow$ & $-3.10 \uparrow$ & 1998 & & 1988 & 0.35 & & 0.41 \\
\hline & Kasım & $-3.26 \uparrow$ & $-0.88 \leftrightarrow$ & $-3.26 \uparrow$ & 1993 & & 1986 & 0.86 & & 0.52 \\
\hline & Aralık & $-2.73 \uparrow$ & $-0.13 \leftrightarrow$ & $-1.34 \leftrightarrow$ & 1992 & & & 1.07 & & \\
\hline & Ocak & $-3.10 \uparrow$ & $-.155 \leftrightarrow$ & $-2.03 \uparrow$ & 1993 & & 1991 & 1.06 & & 0.71 \\
\hline & Şubat & $-1.94 \leftrightarrow$ & $-0.50 \leftrightarrow$ & $-0.90 \leftrightarrow$ & & & & & & \\
\hline & Mart & $3.15 \downarrow$ & $2.19 \downarrow$ & $3.36 \downarrow$ & 1991 & 1992 & 1992 & -1.81 & -1.76 & -1.72 \\
\hline & Nisan & $3.62 \downarrow$ & $3.34 \downarrow$ & $4.97 \downarrow$ & 1990 & 1992 & 1992 & -4.79 & -4.08 & -4.33 \\
\hline & Mayıs & $2.49 \downarrow$ & $1.97 \leftrightarrow$ & $3.46 \downarrow$ & 1990 & & 1988 & -3.16 & & -2.83 \\
\hline & Haziran & $1.37 \leftrightarrow$ & $1.43 \leftrightarrow$ & $1.76 \leftrightarrow$ & & & & & & \\
\hline & Temmuz & $-3.24 \uparrow$ & $-3.53 \uparrow$ & $-4.60 \uparrow$ & 1995 & 1990 & 1992 & 1.28 & 1.73 & 1.29 \\
\hline & Ağustos & $-3.76 \uparrow$ & $-3.38 \uparrow$ & $-5.02 \uparrow$ & 1990 & 1988 & 1988 & 1.00 & 1.96 & 1.30 \\
\hline & Eylül & $-3.11 \uparrow$ & $-3.20 \uparrow$ & $-4.72 \uparrow$ & 1991 & 1988 & 1992 & 0.70 & 1.64 & 1.02 \\
\hline \multirow{12}{*}{ ô } & Ekim & $-3.27 \uparrow$ & $1.64 \leftrightarrow$ & $-1.88 \leftrightarrow$ & 1980 & & & 1.71 & & \\
\hline & Kasım & $-3.84 \uparrow$ & $2.14 \downarrow$ & $2.04 \uparrow$ & 1981 & 1999 & 1977 & 2.01 & -1.64 & 0.75 \\
\hline & Aralık & $-1.74 \leftrightarrow$ & $1.68 \leftrightarrow$ & $-0.39 \leftrightarrow$ & & & & & & \\
\hline & Ocak & $-1.97 \uparrow$ & $0.91 \leftrightarrow$ & $-0.62 \leftrightarrow$ & 1981 & & & 1.48 & & \\
\hline & Şubat & $-0.93 \leftrightarrow$ & $1.45 \leftrightarrow$ & $-0.32 \leftrightarrow$ & & & & & & \\
\hline & Mart & $1.89 \leftrightarrow$ & $1.13 \leftrightarrow$ & $1.69 \leftrightarrow$ & & & & & & \\
\hline & Nisan & $1.54 \leftrightarrow$ & $2.73 \downarrow$ & $3.26 \downarrow$ & & 1993 & 1992 & & -5.01 & -4.13 \\
\hline & Mayıs & $0.62 \leftrightarrow$ & $1.73 \leftrightarrow$ & $2.00 \downarrow$ & & & 1993 & & & -2.60 \\
\hline & Haziran & $-0.37 \leftrightarrow$ & $1.81 \leftrightarrow$ & $0.68 \leftrightarrow$ & & & & & & \\
\hline & Temmuz & $-3.22 \uparrow$ & $-1.71 \leftrightarrow$ & $-3.58 \uparrow$ & 1986 & & 1986 & 2.04 & & 1.54 \\
\hline & Ağustos & $-4.30 \uparrow$ & $-2.46 \uparrow$ & $-4.63 \uparrow$ & 1987 & 2004 & 1986 & 2.29 & 1.87 & 1.76 \\
\hline & Eylül & $-4.06 \uparrow$ & $-1.65 \leftrightarrow$ & $-4.17 \uparrow$ & 1985 & & 1983 & 1.85 & & 1.28 \\
\hline
\end{tabular}

\section{Susurluk Havzası Trend Sonuçları}

Önceki çalışmada kullanılan istasyonlardan trend tespit edilenlerin bir kısmı düzensiz veri ölçümü yapıldığı için bir kısmı da 2000 yılından kısa bir süre sonra kapandığı için bu alışmada Susurluk havzasindan sadece 311 numaralı istasyon kullanılmıştır.

Şekil 6'da 311 no.lu istasyona ait ekim ayı, ilk ve son dönem akım değerleri ve eğilim çizgileri incelendiğinde 2000 yılına kadar olan kısımdaki küçük değerli de olsa azalma eğiliminin son dönemde yön değiştirdiği görülmektedir. $\mathrm{Bu}$ durum farklı dönemlerde farklı trend tespit edilebileceği fikrini desteklemiştir.

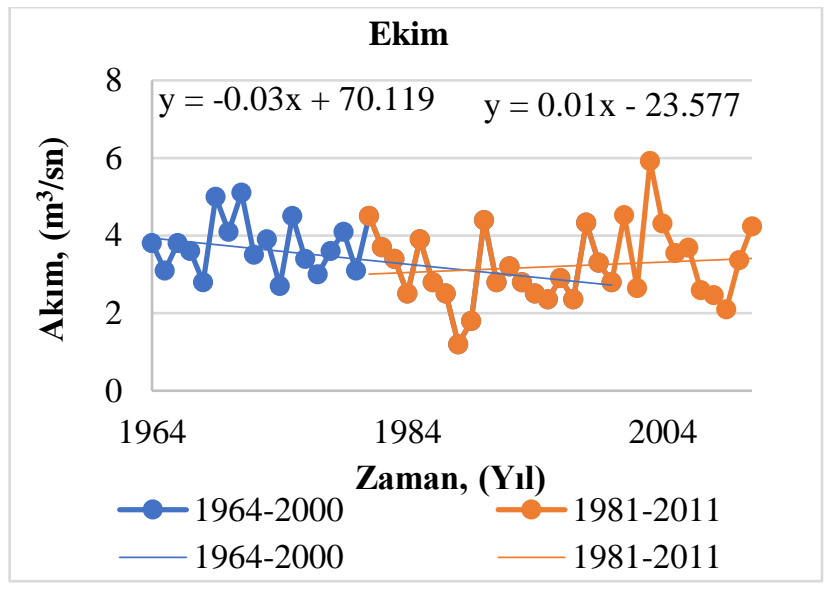

Şekil 6. 311 no.lu istasyon, ekim ayl, ilk ve son dönem akım değerleri ve eğilim çizgileri

Figure 6. Station 311, October, first and last period flow values and inclination lines 
Şekil 7'de son dönem ocak ayı mertebe korelasyon testi grafik sonucu gösterilmektedir. Trend başlangıç yılı $\mathrm{u}(\mathrm{t})$ ve $\mathrm{u}^{\prime}(\mathrm{t})$ grafiklerinin kesim noktasi olan 1983 y1l olarak belirlenmiştir.

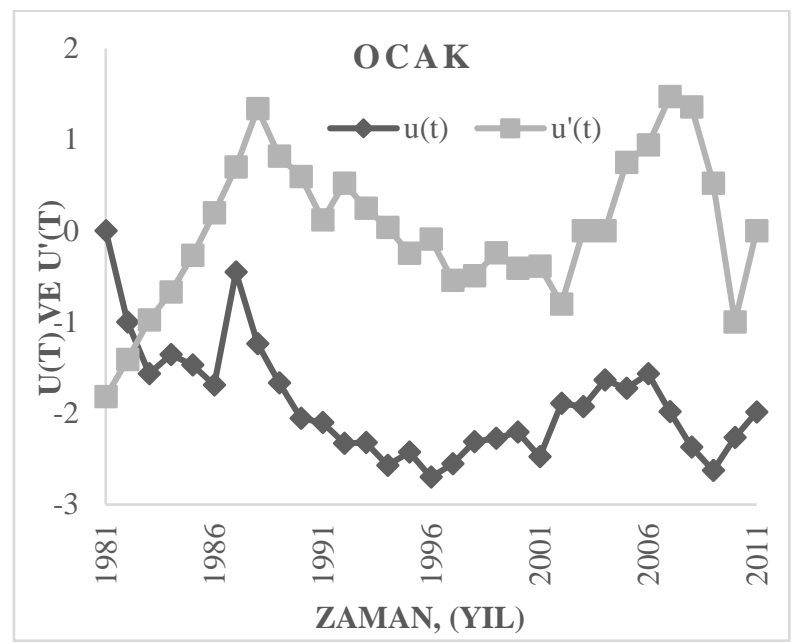

Şekil 7. 311 no.lu istasyon, son dönem, ocak ayl, mertebe korelasyon testi u(t) ve u'(t) grafiği

Figure 7. Station 311, final period, January, rank correlation test $u(t)$ and $u^{\prime}(t)$ graphs
Tablo 2 incelendiğinde ekim ayında ilk dönemde trend belirlenmiş olmasına rağmen son ve uzun dönemde trend tespit edilemediği görülmektedir. Her üç dönemde de trend tespit edilen ayların sadece aralık ve ocak ayları olduğu belirlenmiştir. Ağustos ve eylül aylarında üç dönemde de trend belirlenememiş, ekim ayında sadece ilk dönemde trend belirlenirken nisan ayında ise uzun dönemde trend belirlenmiştir. Belirlenen bütün trendler azalan yöndedir. En yüksek eğim son döneminde ocak ayında -0.99 değeriyle tespit edilmiştir. Trend başlangıç yıllarında 1980'li yıllar ağırlıktadır.

Tablo 2. Susurluk havzası trend analizi sonuçları

Table 2. Trend analysis results of Susurluk basin

\begin{tabular}{|c|c|c|c|c|c|c|c|c|c|c|}
\hline \multirow[b]{2}{*}{ İstasyon } & \multirow[b]{2}{*}{ Aylar } & \multicolumn{3}{|c|}{ Trend Tespiti } & \multicolumn{3}{|c|}{ Trend Başlangıç Yılı } & \multicolumn{3}{|c|}{ Trend Eğimi } \\
\hline & & $\begin{array}{l}1964- \\
2000\end{array}$ & $\begin{array}{l}1981- \\
2011 \\
\end{array}$ & $\begin{array}{c}1964- \\
2011 \\
\end{array}$ & $\begin{array}{l}1964- \\
2000\end{array}$ & $\begin{array}{l}1981- \\
2011 \\
\end{array}$ & $\begin{array}{l}1964- \\
2011 \\
\end{array}$ & $\begin{array}{l}1964- \\
2000 \\
\end{array}$ & $\begin{array}{l}1981- \\
2011\end{array}$ & $\begin{array}{l}1964- \\
2011 \\
\end{array}$ \\
\hline \multirow{12}{*}{$\overline{\vec{m}}$} & Ekim & $2.74 \downarrow$ & $-0.03 \leftrightarrow$ & $1.64 \leftrightarrow$ & 1981 & & & -0.03 & & \\
\hline & Kasım & $3.48 \downarrow$ & $1.29 \leftrightarrow$ & $3.55 \downarrow$ & 1985 & & 1985 & -0.05 & & -0.04 \\
\hline & Aralık & $4.00 \downarrow$ & $2.53 \downarrow$ & $4.56 \downarrow$ & 1985 & 1985 & 1986 & -0.15 & -0.07 & -0.11 \\
\hline & Ocak & $3.46 \downarrow$ & $2.12 \downarrow$ & $4.16 \downarrow$ & 1986 & 1983 & 1986 & -0.19 & -0.99 & -0.15 \\
\hline & Subat & $3.18 \downarrow$ & $1.42 \leftrightarrow$ & $3.56 \downarrow$ & 1988 & & 1986 & -0.28 & & -0.22 \\
\hline & Mart & $3.65 \downarrow$ & $1.17 \leftrightarrow$ & $3.39 \downarrow$ & 1982 & & 1981 & -0.40 & & -0.24 \\
\hline & Nisan & $1.69 \leftrightarrow$ & $0.79 \leftrightarrow$ & $2.88 \downarrow$ & & & 1971 & & & -0.17 \\
\hline & Mayis & $3.21 \downarrow$ & $1.67 \leftrightarrow$ & $4.17 \downarrow$ & 1983 & & 1984 & -0.14 & & -0.12 \\
\hline & Haziran & $3.01 \downarrow$ & $1.2 \leftrightarrow$ & $3.53 \downarrow$ & 1982 & & 1984 & -0.09 & & -0.07 \\
\hline & Temmuz & $2.06 \downarrow$ & $0.64 \leftrightarrow$ & $2.89 \downarrow$ & 1976 & & 1977 & -0.03 & & -0.03 \\
\hline & Ağustos & $1.32 \leftrightarrow$ & $-0.33 \leftrightarrow$ & $1.72 \leftrightarrow$ & & & & & & \\
\hline & Eylül & $1.61 \leftrightarrow$ & $-1.87 \leftrightarrow$ & $1.14 \leftrightarrow$ & & & & & & \\
\hline
\end{tabular}

\section{Sakarya Havzası Trend Sonuçları}

Sakarya havzası, 1203 no.lu istasyona ait ilk ve son dönem akım değerleri ve eğilim çizgilerinin gösterildiği Şekil 8 incelendiğinde son dönem eğilim çizgisinin ilk döneme göre belirgin ölçüde azaldığı görülmektedir. $\mathrm{Bu}$ durum son dönemde veya uzun dönemde istatistiki olarak anlamlı trend bulunamayacağ 1 ya da düşük eğimli trend tespit edilebileceğini göstermiştir. 


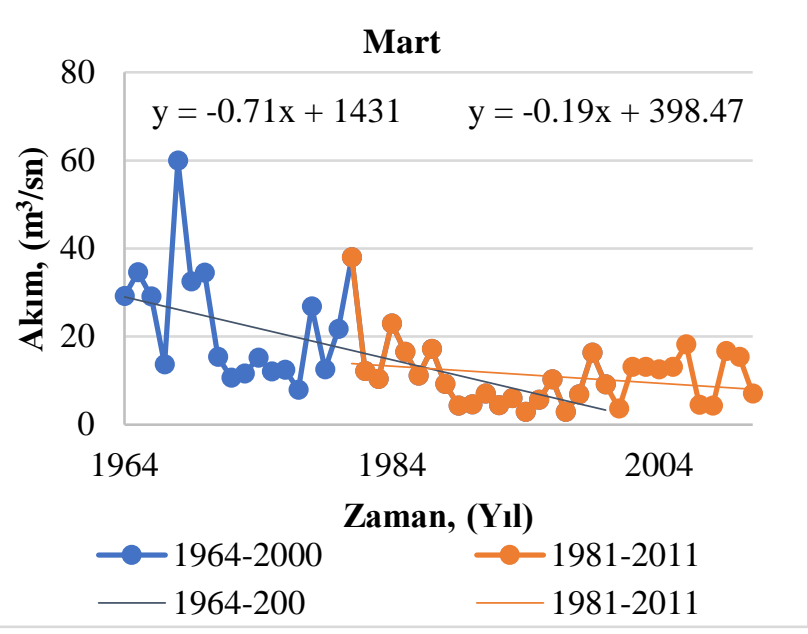

Şekil 8. 1203 no.lu istasyon, mart ayl, ilk ve son dönem akım değerleri ve ĕgilim çizgileri

Figure 8. Station 1203, March, first and last period flow values and inclination lines

Şekil 9'da 1203 numaralı istasyon son dönem, aralık ayı, mertebe korelasyon testi $\mathrm{u}(\mathrm{t})$ ve $\mathrm{u}^{\prime}(\mathrm{t})$ grafiği kesişimi görülmekte olup trend başlangıç y1l 1985 olarak belirlenmiştir.

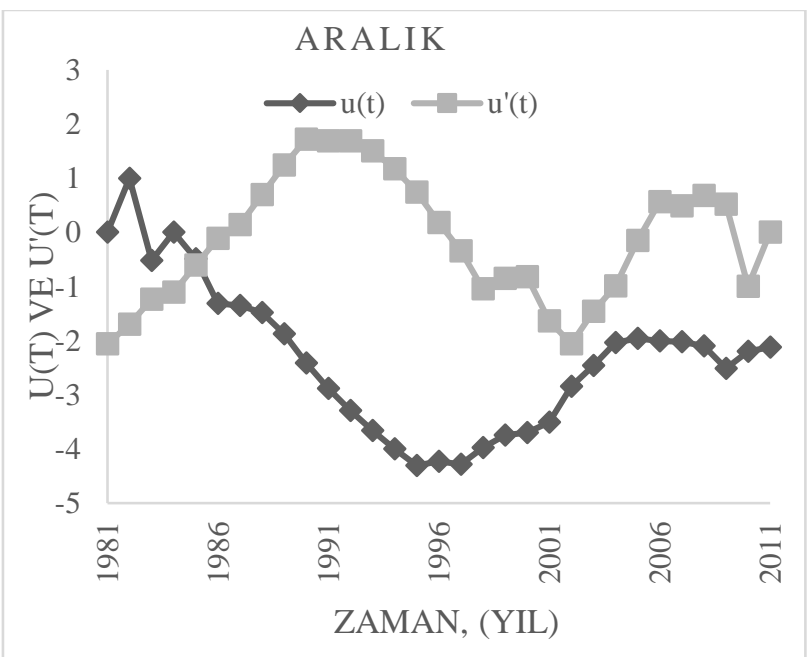

Şekil 9. 1203 no.lu istasyon son dönem, aralık ayl, mertebe korelasyon testi u(t) ve u'(t) grafiği

Figure 9. Station 1203, final period, December, rank correlation test $u(t)$ and $u$ ' $(t)$ graphs

Sakarya havzası, 1224 no.lu istasyona ait ilk ve son dönem akım değerleri ve eğilim çizgilerinin gösterildiği Şekil 10 incelendiğinde son dönem eğilim çizgisinin ilk döneme göre belirgin ölçüde azaldığ 1 görülmektedir. Bu durum uzun dönemde istatistiki olarak anlamlı trend bulunamayacağ ya da düşük eğimli trend tespit edilebileceğini göstermiştir.

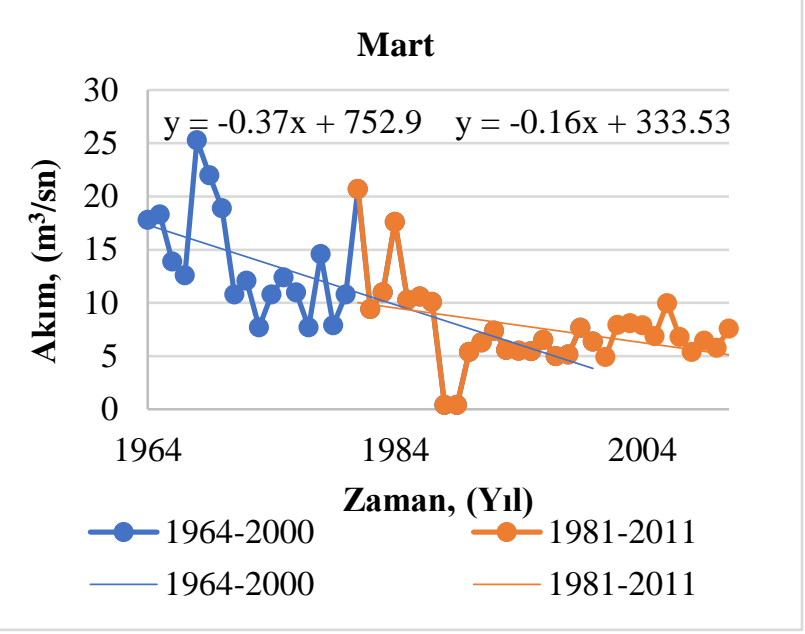

Şekil 10. 1224 no.lu istasyon, mart ayl, ilk ve son dönem akım değerleri ve eğilim çizgileri

Figure 10. Station 1224, March, first and last period flow values and inclination lines

Şekil 11'da 1224 numaralı istasyon uzun dönem, mart ay1, mertebe korelasyon testi $u(t)$ ve $u^{\prime}(t)$ grafiği kesişimi görülmekte olup trend başlangıç y1l 1977 olarak belirlenmiştir.

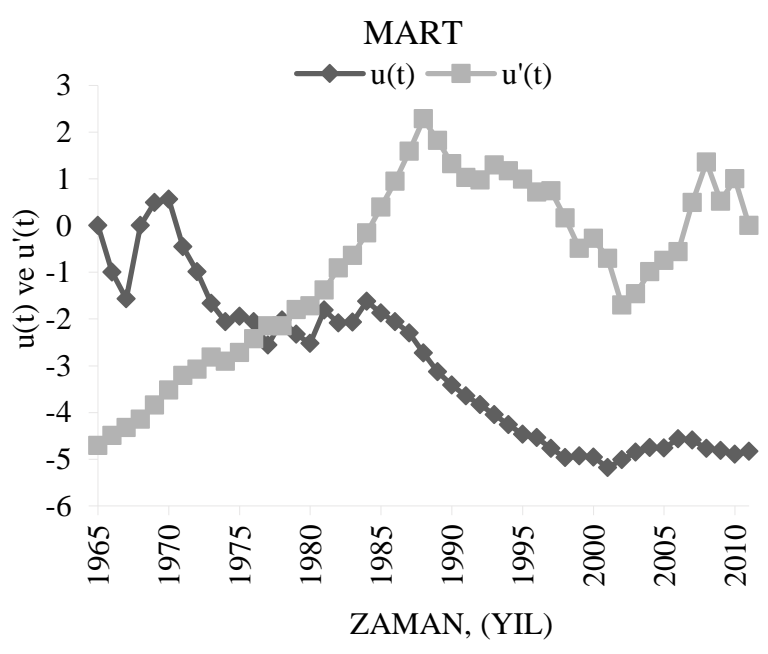

Şekil 11. 1224 no.lu istasyon son dönem, mart ayl, mertebe korelasyon testi u(t) ve u'(t) grafiğ $i$

Figure 11. Station 1224, long period, March, rank correlation test $u(t)$ and $u$ '( $(t)$ graphs

Tablo 3 incelendiğinde her iki istasyonda da ilk dönem eğimlerin son dönem ve uzun dönem eğim değerlerinden genellikle büyük olduğu görülmektedir. İlk dönem ve uzun dönemde bütün aylarda trend belirlenmiştir. Belirlenen bütün trendler azalan yöndedir ancak eğim değerleri çok yüksek değildir. En yüksek eğim 
değeri 1203 numaralı istasyonda ilk dönem mart ayında -0.543 değeriyle hesaplanmıştır. Trend başlangıç yıllarında ağırlık yine 1980'li yıllarda olmakla birlikte 1224 numaralı istasyonun son döneminde belirlenen trendlerde 2000'li y1lların çoğunlukta olduğu görülmektedir. Ayrıca uzun dönemde her iki istasyonda da ilkbahar ve yaz aylarında 1970'li yıllardan başlayan trendler tespit edilmiştir.

Tablo 3. Sakarya havzası trend analizi sonuçları

Table 3. Trend analysis results of Sakarya basin

\begin{tabular}{|c|c|c|c|c|c|c|c|c|c|c|}
\hline \multirow[b]{2}{*}{ İstasyon } & \multirow[b]{2}{*}{ Aylar } & \multicolumn{3}{|c|}{ Trend Tespiti } & \multicolumn{3}{|c|}{ Trend Başlang1ç Y1lı } & \multicolumn{3}{|c|}{ Trend Eğimi } \\
\hline & & $\begin{array}{l}1964- \\
2000 \\
\end{array}$ & $\begin{array}{l}1981- \\
2011 \\
\end{array}$ & $\begin{array}{l}1964- \\
2011 \\
\end{array}$ & $\begin{array}{l}1964- \\
2000 \\
\end{array}$ & $\begin{array}{l}1981- \\
2011 \\
\end{array}$ & $\begin{array}{l}1964- \\
2011 \\
\end{array}$ & $\begin{array}{l}1964- \\
2000 \\
\end{array}$ & $\begin{array}{l}1981- \\
2011 \\
\end{array}$ & $\begin{array}{l}1964- \\
2011 \\
\end{array}$ \\
\hline \multirow{12}{*}{$\stackrel{\overbrace{}}{\text { తి }}$} & Ekim & $4.85 \downarrow$ & $2.24 \downarrow$ & $5.00 \downarrow$ & 1984 & 1984 & 1983 & -0.125 & -0.052 & -0.082 \\
\hline & Kasım & $4.65 \downarrow$ & $2.05 \downarrow$ & $4.80 \downarrow$ & 1986 & 1985 & 1984 & -0.131 & -0.067 & -0.088 \\
\hline & Aralık & $4.63 \downarrow$ & $1.99 \downarrow$ & $4.54 \downarrow$ & 1987 & 1985 & 1985 & -0.238 & -0.074 & -0.142 \\
\hline & Ocak & $4.06 \downarrow$ & $1.97 \downarrow$ & $4.32 \downarrow$ & 1988 & 1983 & 1984 & -0.309 & -0.120 & -0.217 \\
\hline & Şubat & $3.23 \downarrow$ & $1.20 \leftrightarrow$ & $3.10 \downarrow$ & 1986 & & 1984 & -0.323 & & -0.255 \\
\hline & Mart & $4.18 \downarrow$ & $0.46 \leftrightarrow$ & $2.99 \downarrow$ & 1982 & & 1972 & -0.543 & & -0.295 \\
\hline & Nisan & $2.49 \downarrow$ & $0.92 \leftrightarrow$ & $3.06 \downarrow$ & 1971 & & 1971 & -0.329 & & -0.258 \\
\hline & May1s & $3.31 \downarrow$ & $0.98 \leftrightarrow$ & $3.71 \downarrow$ & 1981 & & 1973 & -0.264 & & -0.192 \\
\hline & Haziran & $4.36 \downarrow$ & $0.92 \leftrightarrow$ & $4.01 \downarrow$ & 1979 & & 1972 & -0.260 & & -0.146 \\
\hline & Temmuz & $4.72 \downarrow$ & $1.70 \leftrightarrow$ & $4.59 \downarrow$ & 1982 & & 1976 & -0.125 & & -0.080 \\
\hline & Ağustos & $4.56 \downarrow$ & $1.45 \leftrightarrow$ & $4.64 \downarrow$ & 1982 & & 1976 & -0.095 & & -0.067 \\
\hline & Eylül & $4.63 \downarrow$ & $1.26 \leftrightarrow$ & $4.67 \downarrow$ & 1982 & & 1977 & -0.100 & & -0.075 \\
\hline \multirow{12}{*}{$\underset{\Xi}{\Xi}$} & Ekim & $3.59 \downarrow$ & $2.38 \downarrow$ & $4.38 \downarrow$ & 1984 & 2002 & 1985 & -0.062 & -0.049 & -0.053 \\
\hline & Kasım & $2.72 \downarrow$ & $2.67 \downarrow$ & $4.00 \downarrow$ & 1986 & 2005 & 1993 & -0.038 & -0.048 & -0.045 \\
\hline & Aralık & $4.16 \downarrow$ & $2.62 \downarrow$ & $4.83 \downarrow$ & 1985 & 2006 & 1986 & -0.089 & -0.068 & -0.069 \\
\hline & Ocak & $3.96 \downarrow$ & $2.90 \downarrow$ & $5.00 \downarrow$ & 1986 & 2008 & 1987 & -0.133 & -0.079 & -0.104 \\
\hline & Şubat & $4.18 \downarrow$ & $2.47 \downarrow$ & $4.84 \downarrow$ & 1986 & 2007 & 1986 & -0.170 & -0.083 & -0.124 \\
\hline & Mart & $4.86 \downarrow$ & $1.65 \leftrightarrow$ & $4.80 \downarrow$ & 1981 & & 1977 & -0.309 & & -0.175 \\
\hline & Nisan & $3.37 \downarrow$ & $1.11 \leftrightarrow$ & $3.87 \downarrow$ & 1973 & & 1973 & -0.196 & & -0.155 \\
\hline & May1s & $4.47 \downarrow$ & $1.47 \leftrightarrow$ & $4.72 \downarrow$ & 1981 & & 1977 & -0.175 & & -0.133 \\
\hline & Haziran & $4.03 \downarrow$ & $1.61 \leftrightarrow$ & $4.44 \downarrow$ & 1973 & & 1978 & -0.113 & & -0.090 \\
\hline & Temmuz & $4.70 \downarrow$ & $2.25 \downarrow$ & $4.97 \downarrow$ & 1976 & 2007 & 1978 & -0.098 & -0.060 & -0.073 \\
\hline & Ağustos & $4.71 \downarrow$ & $2.19 \downarrow$ & $5.23 \downarrow$ & 1977 & 2009 & 1981 & -0.088 & -0.050 & -0.072 \\
\hline & Eylül & $3.63 \downarrow$ & $1.57 \leftrightarrow$ & $4.16 \downarrow$ & 1982 & & 1983 & -0.066 & & -0.050 \\
\hline
\end{tabular}

\section{Doğu Akdeniz Havzası Trend Sonuçları}

Doğu Akdeniz havzası 1714 numaralı istasyonun mayıs ayı ilk ve son dönem akım değerleri ve eğilim çizgilerinin yer aldığ 12 incelendiğinde ilk dönem ve son dönem eğilim çizgilerinin eğiminde belirgin fark olduğu görülmektedir. $\mathrm{Bu}$ durum daha önce trend belirlenemeyen aylarda son dönem veya uzun dönemde trend belirlenebileceği ya da belirlenen trend eğimlerinde belirgin farklar ortaya çıkabileceğini akla getirmiştir.

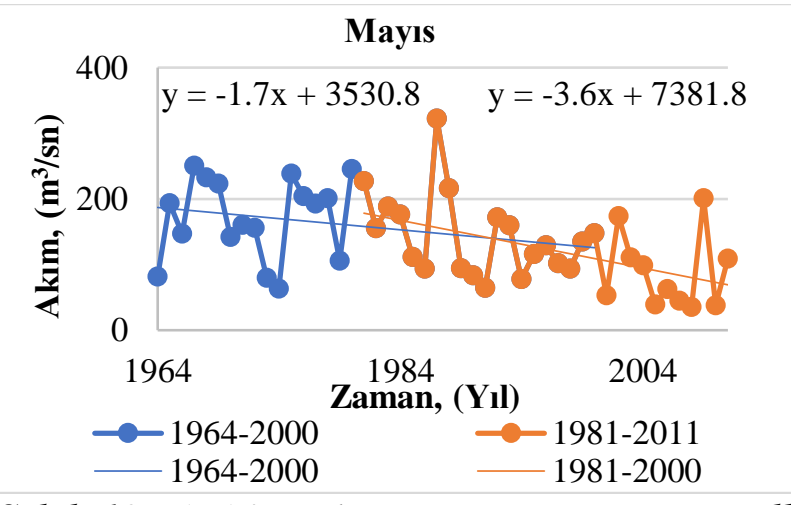

Şekil 12. 1714 no.lu istasyon, mayls ayl, ilk dönem ve son dönem akım değerleri ve eğilim çizgileri.

Figure 12. Station 1714, May, first and last period flow values and inclination lines 
Şekil 13'te 1714 numaralı istasyon son dönem, eylül ayı, mertebe korelasyon testi $u(t)$ ve $u^{\prime}(t)$ grafiği yer almakta olup $u(t)$ ve $u^{\prime}(t)$ grafiklerinin kesim noktasi olan 1989 yılı trend başlangıç yılı olarak belirlenmiştir.

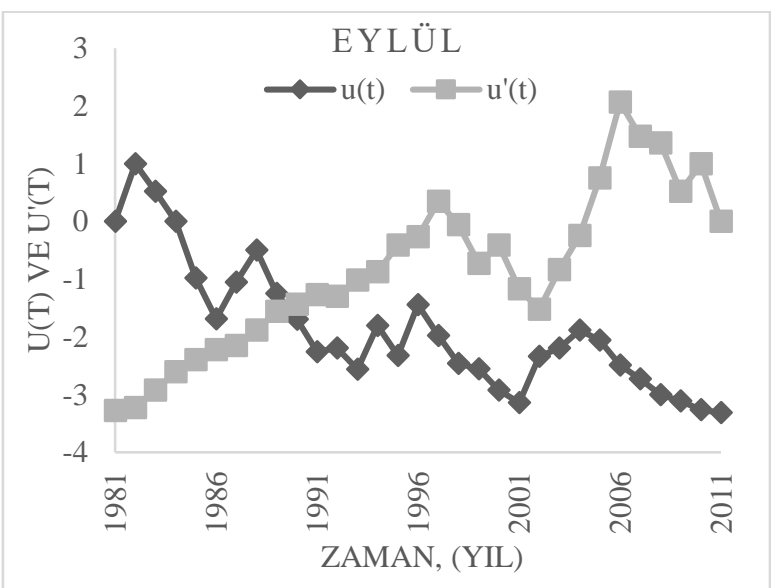

Şekil 13. 1714 no.lu istasyon son dönem, eylül ayl, mertebe korelasyon testi u(t) ve u'(t) grafiği

Figure 13. Station 1714, final period, September, rank correlation test $u(t)$ and $u$ ' $(t)$ graphs
Tablo 4 incelendiğinde kasım ayında hiçbir dönemde trend tespit edilemediği anlaşılmaktadır. Ayrıca ilk dönem ve son dönemde trend tespit edilemeyen aralık ayında uzun dönemde -1.2 eğim değeri ile 1991 yılından başlayan azalan trend tespit edildiği görülmektedir. İlk dönem trend tespit edilemeyen ocak ve nisan aylarında son dönem ve uzun dönem için yapılan hesapta yüksek eğimlerle azalan trend tespit edilmesi akım değerlerinde son dönemlerde belirgin değişim yaşandığına işaret etmektedir. İlk dönem trend tespit edildiği halde son dönemde trend tespit edilemeyen şubat ayında uzun dönem eğim değerinin ilk dönemden düşük olması son dönemde trend tespit edilememesini desteklemektedir. En yüksek eğim değeri nisan ayında son dönemde -5.643 değeriyle tespit edilmiştir. İlk dönemde trend başlangıç yıllarında ağırlık 1980'li yıllarda iken son dönemde 1990 yılları daha belirgindir.

Tablo 4. Doğu Akdeniz havzası trend analizi sonuçları

Table 4. Trend analysis results of the Eastern Mediterranean basin

\begin{tabular}{|c|c|c|c|c|c|c|c|c|c|c|}
\hline \multirow[b]{2}{*}{ İstasyon } & \multirow[b]{2}{*}{ Aylar } & \multicolumn{3}{|c|}{ Trend Tespiti } & \multicolumn{3}{|c|}{ Trend Başlangıç Yı1l } & \multicolumn{3}{|c|}{ Trend Eğimi } \\
\hline & & $\begin{array}{l}1964- \\
2000\end{array}$ & $\begin{array}{l}1981- \\
2011 \\
\end{array}$ & $\begin{array}{l}1964- \\
2011 \\
\end{array}$ & $\begin{array}{l}1964- \\
2000\end{array}$ & $\begin{array}{l}1981- \\
2011 \\
\end{array}$ & $\begin{array}{l}1964- \\
2011 \\
\end{array}$ & $\begin{array}{l}1964- \\
2000 \\
\end{array}$ & $\begin{array}{l}1981- \\
2011 \\
\end{array}$ & $\begin{array}{l}1964- \\
2011 \\
\end{array}$ \\
\hline \multirow{12}{*}{$\stackrel{ \pm}{I}$} & Ekim & $3.05 \downarrow$ & $4.18 \downarrow$ & $5.02 \downarrow$ & 1991 & 1995 & 1996 & -0.500 & $\begin{array}{c}- \\
0.7963\end{array}$ & -0.645 \\
\hline & Kasım & $-0.19 \leftrightarrow$ & $1.45 \leftrightarrow$ & $0.63 \leftrightarrow$ & & & & & & \\
\hline & Aralık & $1.06 \leftrightarrow$ & $1.51 \leftrightarrow$ & $2.33 \downarrow$ & & & 1991 & & & -1.200 \\
\hline & Ocak & $1.89 \leftrightarrow$ & $2.55 \downarrow$ & $3.04 \downarrow$ & & 1988 & 1991 & & -2.59 & -2.567 \\
\hline & Şubat & $1.96 \downarrow$ & $1.39 \leftrightarrow$ & $2.62 \downarrow$ & 1989 & & 1987 & -2.500 & & -1.818 \\
\hline & Mart & $3.53 \downarrow$ & $2.35 \downarrow$ & $3.95 \downarrow$ & 1989 & 1991 & 1984 & -3.442 & -2.137 & -2.570 \\
\hline & Nisan & $1.25 \leftrightarrow$ & $2.62 \downarrow$ & $3.13 \downarrow$ & & 2004 & 1994 & & -5.643 & -4.000 \\
\hline & Mayis & $1.96 \downarrow$ & $2.80 \downarrow$ & $3.73 \downarrow$ & 1988 & 1994 & 1994 & -2.212 & -3.54 & -2.763 \\
\hline & Haziran & $2.95 \downarrow$ & $3.45 \downarrow$ & $4.53 \downarrow$ & 1988 & 1988 & 1991 & -1.177 & -1.579 & -1.294 \\
\hline & Temmuz & $2.54 \downarrow$ & $3.57 \downarrow$ & $4.32 \downarrow$ & 1985 & 1998 & 1989 & -0.561 & -0.788 & -0.670 \\
\hline & Ağustos & $3.18 \downarrow$ & $3.29 \downarrow$ & $4.63 \downarrow$ & 1988 & 1992 & 1988 & -0.500 & -0.623 & -0.541 \\
\hline & Eylül & $3.53 \downarrow$ & $3.26 \downarrow$ & $4.72 \downarrow$ & 1988 & 1989 & 1986 & -0.490 & -0.585 & -0.500 \\
\hline
\end{tabular}

\section{Sonuçlar}

Çalışmada elde edilen en dikkat çekici sonuçlardan birisi Yeşilırmak havzası 1402 numaralı istasyon kasım ayında gerçekleşmiştir. İlk ve uzun dönemde artan trend tespit edilen bu ayda son dönemde tam tersi yönde trend tespit edilmesi bu tür çalışmalarda veri aralığını tespit ederken dikkatli olunması gerektiğini ve özellikle uzun süreli verilerle yapılan analizlerde 
ayrıca son dönem verileri için de hesap yapılması gerektiğini göstermiştir.

Susurluk havzası, 311 numaralı istasyonda ocak ayı için yapılan analizde son dönem için belirlenen trend eğim değeri uzun dönem için belirlenen trend eğim değerinden 6.6 kat fazla hesaplanmıştır. $\mathrm{Bu}$ durum akım verilerindeki azalma eğilimin son dönemde daha belirgin hale geldiğini göstermiştir.

Sakarya havzasında son dönemde trend tespit edilemeyen aylar incelendiğinde uzun dönem eğim değerlerinin ilk dönemde tespit edilen eğim değerlerinden küçük olduğu anlaşılmıştır. Bu durum son dönemde trend tespit edilememesini açıklar niteliktedir.

Uzun dönem için yapılan analizde trend başlangıç yılları incelendiğinde toplam 29 ayda 1980'li, 14'er ayda 1970'li ve 1990'l1 yıllarda trend başlangıcı tespit edildiği görülmektedir. $\mathrm{Bu}$ sonuç, dünyada iklim değişikliği üzerine hazırlanan raporlarda insan faktörü sonucunda, yüzey sıcaklıklarının 1980'lerin başında belirginleşmesi sonucuyla uyumludur [34, 35].

Ayrıca Türkeş [36] tarafından ülkemizdeki iklim değişikliği ve kuraklık üzerine yapılan çalışmada, ısınma eğiliminin, şehirleşme seviyesi fark etmeksizin hemen hemen bütün istasyonlarda 1980'li yıllarla birlikte hızlandığ tespit edilmiş olup iklim değişikliği sinyali, kimi istasyonda 1980'li yılların ortasında, kimilerinde ise 1990'ların başında gerçekleştiği belirlenmiştir.

Aynı çalışmada Türkiye yağışlarındaki eğilimler incelenmiş olup kuraklaşma eğiliminin istasyonların bir k1smında 1970'li y1lların başında, bir kısmında ise 1980'li yılların başında etkili olduğu tespit edilmiştir. 1980'li yıllarda azalan yağış ve artan sıcaklık değerleri tespit edilmiş olması akım değerlerinde özellikle 1980'li y1llarda başlayan azalan eğilimler tespit edilmesi sonucunu desteklemektedir.

$\mathrm{Su}$ kaynaklarının planlanmasında trend metotlarından yararlanılacağında, daha önce trend belirlenen bir istasyonda sonraki dönemde tam tersi bir eğilim görülebileceği, eğim değerlerinde belirgin değişimler yaşanabileceği ya da uzun süreli veride trend olmamasına rağmen daha kısa süreli veride eğim belirlenebileceği göz önünde bulundurulmalıdır. Özellikle akım verisi için sonuçların bölgenin yağış ve sicaklık trend sonuçları ile değerlendirilmesi gelecekle ilgili daha sağliklı ipuçlarına ulaşmayı sağlayacaktır.

\section{Kaynaklar}

[1] Kumar, N., Tischbein, B., Beg, M. K., (2019). Multiple trend analysis of rainfall and temperature for a monsoon-dominated catchment in India, Meteorology and Atmospheric Physics, 131, 10191033.

[2] Huth, R, Pokorn, L., (2004). Parametric versus nonparametric estimates of climatic trends. Theor Appl Climatol 77:107-112.

[3] Van Belle, G. and Hughes, J. P., (1984). Nonparametric tests for trend in water quality, Water Resour Res, 20, 1, 127-136.

[4] Helsel, D. R., Hirsch, R. M., (1988). Applicability of the t-Test for Detecting Trends in Water Quality Variables by Robert H. Montgomery and Jim C. Loftis. J Am Water Resour Assoc, 24, 201-204.

[5] Zhang, X., Vincent, L. A., Hogg, W. D., Niitsoo, A., (2000). Temperature and precipitation trends in Canada during the 20th century, Atmos Ocean, 38, 395-429.

[6] Liu, R. Q., Jacobi, C., Hoffmann, P., Stober, G., Merzlyakov, E. G., (2010). A piecewise linear model for detecting climatic trends and their structural changes with application to mesosphere/lower thermosphere winds over Collm, Germany, $J$ Geophys Res, 115,1-10.

[7] Weng, S. P., (2010). Changes of diurnal temperature range in Taiwan and their large-scale associations: univariate and multivariate trend analyses, J Meteorol Soc Jpn Ser II, 88, 203-226.

[8] Sansigolo, C. A., Kayano, M. T., (2010). Trends of seasonal maximum and minimum temperatures and precipitation in Southern Brazil for the 1913-2006 period, Theor Appl Climatol, 101, 209-216.

[9] Serrano, A., Garcia, A. J., Mateos, V. L., Cancillo, M. L., Garrido, J., (1999). Monthly modes of variation of presipitation over the iberion peninsula, J. Climate, 12: 2894-919.

[10] Duhan, D., Pandey, A., (2013). Statistical analysis of long term spatial and temporal trends of precipitation during 1901-2002 at Madhya Pradesh, India, Atmos Res, 122,136-149. 
[11] Limsakul, A., Singhruck, P., (2016). Long-term trends and variability of total and extreme precipitation in Thailand, Atmos Res, 169, 301-317.

[12] Partal, T., Kâhya, E., (2006). Trend analysis in Turkish precipitation data, Hydrol Process, 20, 20112026.

[13] Dash, S. K., Jenamani, R. K., Kalsi, S.R., Panda, S. K., (2007). Some evidence of climate change in twentieth-century India, Clim Chang, 85, 299-321.

[14] Subash, N., Ram Mohan, H. S., Sikka, A. K., (2011). Decadal frequency and trends of extreme excess/defcit rainfall during the monsoon season over diferent meteorological subdivisions of India, Hydrol Sci J, 56, 7, 1090-1109.

[15] Tabari, H., Taye, M. T., Willems, P., (2015). Statistical assessment of precipitation trends in the upper Blue Nile River basin, Stoch Environ Res Risk Assess, 29, 1751.

[16] Pingale, S., Adamowski, J., Jat, M., Khare, D., (2015). Implications of spatial scale on climate change assessments, $J$ Water and Land Dev, 26, 3756.

[17] Alobaidi, A.H., (2015). Analysis of relative humidity in Iraq for the period 1951-2010, Int J Sci Res Publ, 5, 5, 515-524.

[18] Wijngaarden, V., Vincent, L. A. (2003). Trends in relative humidity in Canada from 1953-2003. Report prepared for Climate Research Barnchm Meteorological Service, Canada.

[19] Dyer, J. L., Mote, T. L., (2006). Spatial variability and trends in observed snow depth over North America, Geophys Res Lett, 33, L16503.

[20] Kunkel, K. E., Robinson, D. A., Champion, S., Yin, X., Estilow, T., Frankson, R. M., (2016). Trends and Extremes in Northern Hemisphere Snow Characteristic, Curr Clim Chang Rep, 2, 65-73.

[21] Chattopadhyay, N., Hulme, M., (1997). Evaporation and potential evapotranspiration in India under conditions of recent and future climate change, Agric For Meteorol, 87, 55-73.

[22] Aksoy, B., (1999). Analysis of changes in sunshine duration data for Ankara, Turkey, Theor Appl Climatol, 64, 229-237.

[23] Rahimzadeh, F., Pedrama, M., Krukb, M. C., (2014). An examination of the trends in sunshine hours over Iran, Meteorol Appl, 21, 309-315.
[24] Chiew, F. H. S., McMahon, T. A., (1993). Detection of trend or change in annual flow of Australian rivers, Int J Climatol., 13, 643-653.

[25] Douglas, E. M., Vogel, R. M. and Kroll, C. N., (2000). Trends in foods and low flows in the United States: impact of spatial correlation, J Hydrol, 240, 90-105.

[26] Zhang, X., Harvey, K. D., Hogg, W. D., Yuzyk. T. R., (2001). Trends in Canadian streamflow, Water Resour Res, 37, 987-998.

[27] Kâhya, E., Kalayc1, S., (2004). Trend analysis of stream flow in Turkey, J Hydrol, 289, 128-144.

[28] Özel, N., (2004). Türkiyedeki nehir akımları aylık verilerinin parametrik olmayan yöntemlerle trend analizi. Yüksek Lisans Tezi. Selçuk üniversitesi, Fen Bilimleri Enstitüsü, Konya.

[29] DSI, (2019). Akım gözlem yıllıkları, http://www.dsi.gov.tr/faaliyetler/akim-gozlemyilliklari, (1.10.2019).

[30] Sen, P. K., (1968). Estimates of the Regression Coefficient Based on Kendall's Tao, J. Am. Stat. Assoc., 63, 1379-1389.

[31] Lettenmaier, D. P., (1976). Detection of trends in water qualitiy data from records with dependent observations, Water Resour Res, 12, 5, 1037-1046.

[32] İçağa, Y., (1994). Analysis of trends in water quality using nonparametric methods. Yüksek Lisans Tezi, Dokuz Eylül Üniversitesi, Fen Bilimleri Enstitüsü, İzmir.

[33] Sneyers, R., (1990). On the Statistical Analysis of Series of Observations. World Meteorogical Organization, No.415, Geneva. 192.

[34] IPCC. (2001). Climate Change 2001: The Scientific Basis. Contribution of Working Group I to the Third Assessment Report of the Intergovernmental Panel on Climate Change, Houghton, J.T., et al., Cambridge University Press: Cambridge and New York. 823.

[35] IPCC. (2007). Climate Change 2007: The Physical Science Basis. Contribution of Working Group I to the Fourth Assessment Report of the Intergovernmental Panel on Climate Change, Solomon, S., et al., Cambridge University Press: Cambridge and New York. 996.

[36] Türkeş, M., (2012). Türkiye'de gözlenen ve öngörülen iklim değişikliği, kuraklık ve çölleşme, Ankara Üniversitesi Çevrebilimleri Dergisi, 4, 2, 132. 